\title{
The Principal Is Often Overlooked
}

\author{
Marshall Shearer, M.D. ${ }^{1}$
}

ABSTRACT: The role of the school principal in the psychiatric evaluation of one of his pupils is important, but often overlooked. With all referrals, except perhaps the withdrawn child, he has made some effort to improve the situation. The nature and extent of this involvement varies greatly, and knowledge of it is often essential to therapeutic planning. Countertransference is a phenomenon principals are not trained to be aware of, but which is especially important to recognize. The uses of the psychiatric consultant by a school district are discussed. Perhaps the greatest impact the consulting psychiatrist can have on mental health in the schools is the open recognition he gives the teacher and principals that their intuitive approach to the vast majority of the problems of their charges is sound and helpful.

The psychiatrist who serves as consultant to a school system often finds himself called upon to understand the interactions of a school organization, as well as the problems of the individual child. To a somewhat less conspicuous extent, the subjective attitudes of school person* nel are also revealed in the investigation of the school-age child who is referred for evaluation or treatment to an agency outside the school system itself. While the actual request for psychiatric help is more frequently made by a visiting teacher (a teacher-social worker in the schools) or school diagnostician, such a request almost without exception is made with at least the awareness and approval of the school principal. He carries, after all, the primary responsibility for the morale and smooth functioning of his

I. Dr. Shearer, a child psychiatrist, is Instructor, Department of Psychiatry, University of Michigan Medical School, Ann Arbor, Michigan 48104, Assistant Director, In-Patient Services, Children's Psychiatric Hospital, University of Michigan Medical Center, and Psychiatric Consultant to the Ann Arbor Public Schools. The author has consulted in four school districts; the case material presented did not occur in Ann Arbor. 


\section{Community Mental Health Journal}

school, and children who have been disruptive have usually been through the disciplinary channels which he heads.

The principal is less likely to become involved with the withdrawn child, but the class funny boy, the acting-outer, the class or community scapegoat or reject he knows well. He requires no assistance with the majority of these cases, but when he does and referral is made, the nature and extent of this previous involvement can be crucial information to the proper handling of the given child's difficulties. If the involvement has been more than superficial, the psychiatrist should be alert for transference and countertransference problems.

In school systems which employ visiting teachers (VTs), these are usually deployed by assignment to only 2 or 3 schools within the system. Because of her training, the perspective of working with more than one teacher in a school, her awareness of the larger picture which includes the child's home environment, and her position outside the direct line of authority, the VT often is aware of subjective, interactional factors in the child's school situation. Her position does include, however, assisting the classroom teacher with problem pupils and she must maintain good rapport with each of her principals to function effectively. Even though she serves several schools, she is, within each school, dependent on the principal in many ways, and works closely with him. She may, therefore, hesitate to pass along to a consultant information which she fears may put the principal in a bad light, particularly when she does not know the consultant well.

\section{CASES}

One visiting teacher from a distant school district, for example, tried to make a compromise during an evaluation at the agency by saying, "He (the boy) is a potential school dropout." This was quite obvious and said out of context. After several pressing questions, it was learned that the assistant principal was going to "allow" this extremely disruptive and troublesome 15-year-old boy to drop out of school on his sixteenth birthday. "Allow" was then understood to mean "encourage" or "see to it that ...." However, without a psychiatrist's statement that nonattendance was in the best interest of the boy, the school board required that the school make every effort to prevent his dropping out. The assistant principal's motivation was to obtain such a statement. The VT knew the boy didn't stand a chance of "making it in school" with the assistant principal's current attitude. She also knew that this attitude would not be modified by a letter or phone call from the agency. It did not occur to her to ask that agency personnel visit the school and confer with the assistant principal in person. The principal was caught in a transference-countertransference problem; the VT was caught in her dilemma; the psychiatrist was almost caught in the dark.

Principals should not be expected to understand the transference phenomenon, since it is not part of their training. They utilize their own personalities readily and freely (as they should) in dealing with pupils and their problems. The VT usually knows well the typical techniques the principals 
use with various behavior problems in the schools she serves. She will also have information about the pupil's teacher, classmates, siblings, and community. The following case history from consulting work in another school district is illustrative of the importance of a private talk with the VT before evaluating the child.

The coordinator of special services received an urgent call requesting the services of the school psychiatrist to see the "worst boy in the school." This situation was extreme. The VT had not previously been involved. The consultant arranged to meet the VT at the school, feeling that it would be educational for her to sit in on the interview. However, an opportunity to talk privately with her beforehand was not arranged. The consultant interviewed the boy, his divorced mother, two teachers, and the principal. The principal presented the boy as a lying, stealing, and calloused, dangerous culprit. He presented notes of the times he had seen the boy over the past 2 years. The earlier notes had a ring of warmth, with remarks of improvement such as, "Hasn't sassed a teacher in three weeks now." The later notes were bitter, with remarks such as, "I tried to talk to him for an hour but he wouldn't listen." Essentially the boy had a very low self-esteem and a poor masculine identity. He was bolstering both by fighting, attempting to be the class funny boy, and otherwise attempting to place himself above the teachers. Although the boy had been disruptive in class and had attracted attention to himself for 2 years, he had never been referred for VT service. The VT knew the boys who were his friends. They were mischievous and dare-devilish, but would respond to firm controls, warmly applied. The boy's two teachers were surprised that the consultant had been asked to see this particular boy. They thought he was a nuisance and disruptive, but felt quite warmly toward him. Only after clearly seeing these attitudes did the principal modify his insistence that the boy be sent to an institution and agree to permit the VT an opportunity to work with him.

Not only did the VT know the boy's group, but she knew that the boy had previously been considered the "principal's pet," and he had been getting the group into increasing trouble for the past 6 weeks. This change was related to a new and previously unknown "uncle" moving into the house with his divorced mother. The VT also knew that initially the principal tended to be warm and fatherly with most pupils, but when his approach didn't produce the desired results, he would adopt a "Dutch uncle" approach. In this instance, a 5-minute conference between VT and consultant prior to the evaluation would have saved considerable time.

The above case illustrates another important consideration-the narcissistic injury to the principal. The warm fatherly approach is often successful and in this case had initially been so. Some children test the principal's affection by making frequent demands upon the relationship; some make unrealistic demands; others may try to see how far they can go in misbehavior and still maintain the relationship. The principal then may become frightened at the "sticky involvement" or may suffer a blow to his own self-esteem when the boy acts out. The principal may react to the narcissistic injury by a need to make the boy appear all bad, out of an unrecognized fear of seeing someone else succeeding where he has failed. If no 
one can "do anything" with the boy, the principal escapes narcissistic injury. The following are the hallmarks of this situation:

I. Absence of previous referral to the VT in the face of a chornic problem.

2. An urgent request for psychiatric help out of channels, bypassing the VT or the diagnostician or others.

3. Sudden explosion(s) in a chronic problem.

4. The use of the expression, "He is the worst boy in school," or other negative superlatives.

5. Lack of concern by the pupil's classroom teacher(s).

6. The principal's desire, overtly or tacitly expressed, that the boy be placed outside his principalship.

Once this situation is recognized, one should first indicate that the extent and severity of the behavior problem is recognized and appreciated. Some statements aimed at putting this child's problem in perspective with other problems in the school and in any proposed new locale are helpful. An "out" should be given the principal. This is readily done when the principal's approach has been therapeutic, but the rate of improvement he expected was unrealistic. The consultant may point out the deterioration within the child's home situation which the principal may not be in a position to be aware of, or may acknowledge the unrealistic demands placed upon him by the child which realistically no one could have met. The consideration of possible alternative courses of action with the reasons for their exclusion from further consideration should be done aloud and in some detail. To then solicit the principal's participation as an integral part of the new program even though his task may not be a pleasant one is helpful. If the child is to remain in the same school and be handled by the VT, ongoing support for the VT by the consultant in her contact with the principal is essential.

The involvement of the principal is usually most beneficial and may be absolutely necessary. However, the VT's picture of the boy's homelife is generally more complete, dynamically perceived, and less static than the principal's. The teacher-principal-VT team works wonders in many cases if properly correlated. In some cases, the VT may not see the child herself but may serve as a sounding board for the principal or keep him posted on developments in the child's home.

Many children, especially those without fathers, may get into frequent minor difficulty in order to be sent to the principal. This can be suspected if the difficulty is minor, frequent, and if the interview with the principal ends up with kind words and a pat on the back. In this situation, other opportunities for the boy to foster a relationship with his principal should be made available. The boy should not need to misbehave in order to get the kind words which indicate concern and acceptance. If the demands for 
acceptance, love, or approval from the teacher or principal become excessive, they cannot be met and ultimately the child will feel rejected. Unless this is pointed out to the child by the principal or teacher, it will result in the child's feeling justified in his resentment and hatred. Subsequently, the principal and teacher may feel guilty, perhaps unconsciously, for not meeting his unrealistic demands and this in turn may lead to overindulgence and the cycle will repeat itself.

There are a number of cases in which the underlying motive for the referral for evaluation is simply the need for reassurance on the part of the principal or teacher-reassurance that the child's program is the best one available and that they are progressing satisfactorily with the pupil's problems. This doubt and self-doubt is usually due to progress not being made as rapidly or smoothly as expected. Most often they have been overoptimistic. They are usually conscientious, intuitive, and capable. If they are given license to do what they intuitively feel needs to be done, things will go quite well. This function of reassuring school personnel that they are doing a good job on an adequate program has perhaps the largest mental health impact of any function the psychiatric consultant can perform.

Principals as administrators are responsible for the morale and smooth functioning of their school. On occasion they may need to enlist the prestige of the psychiatrist to convey to teachers, students, and the public the degree of concern by obtaining a quick psychiatric opinion.

A 14-year-old boy hit a male teacher in the face. He had had two encounters with the police and had become a VT case in which progress was apparently being made. A prompt emergency psychiatric interview was held in the school to evaltrate his program and to emphasize the gravity of the situation, not only to the boy but also to the rest of the school and to the community. This was done without undo display or fanfare. No structural change was deemed advisable in his program. However, the tension among the student body decreased markedly.

As an administrator, the principal may on occasion have to take a stand which will be opposed by the child's parents. The "impartial" psychiatric evaluation by a psychiatrist not employed by the school may relieve the situation. In rare instances the school's consulting psychiatrist may serve as mediator. In the following case where mediation was attempted, the parents became antagonistic and negativistic to the school psychiatrist whom they perceived as the greater authority and could then ally themselves with the school and principal.

An overprotected 4 th grade boy with an IQ of 132 was absent from school about 2 out of 3 days in the winter because of "bad weather." He lived six blocks from school. No buses serve the school, as all children were considered to live within walking distance. He was disruptive in class (talking out loud and not staying in his seat, though not hyperactive). His parents were proud, idealistic, and quite suspicious. They felt rejected in the neighborhood "because of the father's (mild olive) complexion." The mother was generally overindulgent. Visiting teacher 
involvement had been refused. When the school finally forced a psychiatric evaluation by threat of suspension, the parents would not make arrangement through the school or even let the school know which agency they would go to. They presented the case to a private psychiatrist as a question of "psychosis," and manipulated him into cutting his usual evaluation time in half. The school received a report from him saying that the boy was not psychotic, not a danger to himself or others, and ought not be excluded from school. At this time the school's consulting psychiatrist's opinion was sought. A morning's conference with parents, principal, VT, assistant school superintendent, and consulting psychiatrist was arranged. After all positions had been stated, the consultant moved to clarify and confront. The parents shifted their animosity and negativism from the school administrators to the psychiatrist and the VT. The principal perceived this, set certain expectations which the parents agreed to and then compromised with the parents against the VT and psychiatrist. VT contact was held in reserve. During the next three semesters things went fairly well. Whenever the parents would begin to become negativistic to the school, a call from the VT inquiring in a friendly way how things were going would meet negativism but would result in cooperation with the teacher and principal. In this way their shift of obstinacy toward the "greater authority," as they perceived it, was maintained.

The example also illustrates the grounds such a set of parents might use to charge collusion had the consulting psychiatric also been the evaluating psychiatrist at the outside agency where an evaluation was sought. Since one cannot foretell which parents might harbor such feelings, it is well for the psychiatrist to refrain from seeing cases from his consultive school district at his agency.

\section{Conclusion}

It has been noted that the principal is the first person the classroom teacher turns to for help with a pupil's problems, and that no child under his aegis is referred for help with emotional problems without his awareness and approval. An understanding of the general nature and extent of the principal's prior and continuing involvement may be crucial to the success of any therapeutic program suggested by the psychiatric consultant. We have discussed some common emotional problems a principal encounters in pupils and some of his methods of meeting them. Special attention has been devoted to the recognition and handling of a principal's problem of countertransference, a phenomenon he is not trained to recognize.

Perhaps the greatest impact the consulting psychiatrist can have on mental health in the schools is the open recognition he gives the teacher and principals that their intuitive approach to the vast majority of the problems of their charges is sound and helpful. 